\title{
PANDEMIA E EQUILÍBRIO ORÇAMENTAL, UM ESTUDO COMPARATIVO (BRASIL, ZONA EURO, ESTADOS UNIDOS E REINO UNIDO)
}

\section{PANDEMIC AND BUDGET BALANCE, A COMPARATIVE STUDY (BRAZIL, EUROZONE, UNITED STATES AND UNITED KINGDOM)}

RESUMO: A luta contra a pandemia gerada pela Covid 19 e os planos de recuperação econômica implicarão um desperdício significativo da despesa pública, o que ameaça seriamente os equilíbrios financeiros dos Estados. Nos últimos tempos, muitos países levaram a cabo reformas constitucionais para introduzir estes equilíbrios. A forma como estes equilíbrios foram introduzidos e as narrativas e os consensos gerados dependerão em grande medida da resposta que os Estados forem capazes de dar. Uma análise da situação em diferentes países, como os Estados Unidos, o Reino Unido, o bloco da zona euro ou o Brasil, proporcionar-nos-á importantes surpresas, numa altura em que uma boa compreensão do significado desses equilíbrios pode ser crucial para a recuperação econômica.

Palavras-Chave: saldos financeiros; recuperação econômica; pandemia de Covid-19; finanças funcionais; teoria monetária moderna.

\footnotetext{
${ }^{1}$ Professor de Direito Constitucional da Universidade de Granada, Espanha. Doutor em Direito pela Universidade de Granada. E-mail: miguelarjona@ugr.es.
} 
ABSTRACT: The fight against the pandemic generated by Covid 19 and the economic recovery plans will mean a significant waste of public expenditure, which seriously threatens the financial balances of the states. In recent times, many countries have carried out constitutional reforms to introduce these balances. The way in which these balances have been introduced, and the narratives and consensus generated, will depend largely on the response that the states are able to deploy. An analysis of the situation in different countries such as the United States, the United Kingdom, the Eurozone bloc or Brazil will provide us with important surprises, at a time when a good understanding of the meaning of these balances may be crucial for economic recovery.

KEYWORDS: financial balances; economic recovery; Covid-19 pandemic; functional finance; modern monetary theory.

\section{A PANDEMIA E O EQUILÍBRIO FINANCEIRO DO ESTADO}

A partir da data deste artigo com quase 400.000 mortes e 6,7 milhões de casos diagnosticados no mundo, a pandemia de Covid 19 transformou significativamente a vida de quase toda a população mundial ${ }^{2}$, espalhando medidas preventivas tão invasivas como o confinamento dos cidadãos às suas casas, a limitação da sua liberdade de circulação ou reunião, a utilização obrigatória de máscaras ou a manutenção de distâncias para as relações interpessoais, o recurso obrigatório ao teletrabalho e, naturalmente, uma grande tensão nos sistemas de saúde de quase todos os países do mundo.

Todas estas medidas, que só os Estados estão em condições de exigir e aplicar eficazmente, justificaram não só o papel dos poderes públicos enquanto garantes dos direitos humanos, nomeadamente o direito à saúde e à vida, mas também a sua responsabilidade na organização das relações produtivas e, em última análise, da economia dos seus países.

Como é sabido, a natureza da crise que enfrentamos é singularmente diferente da de recessões anteriores, uma vez que, para além de o ciclo económico dar sinais de esgotamento, foram os próprios Estados, no exercício da sua responsabilidade, que optaram por induzir a redução e mesmo a "hibernação" da atividade econômica não essencial.

Perante o novo fenômeno, as autoridades públicas foram obrigadas a tomar medidas (sob a forma de ajudas, subsídios e investimentos públicos) tanto para evitar a destruição do seu tecido produtivo como para relançar a atividade econômica, uma vez passada a fase mais difícil da pandemia, bem como para reforçar os seus sistemas de saúde. Embora seja ainda demasiado cedo para avaliar

\footnotetext{
${ }^{2}$ Os dados são da University Johns Hopkings e correspondem a 6 de Junho de 2020. Os dados atualizados estão disponíveis em: https://coronavirus.jhu.edu/map.html
} 
estas medidas, não pode haver dúvidas de que irão aumentar os défices orçamentais dos Estados, perturbando o seu planeamento financeiro, pelo que, em princípio, deverão conduzir a consequências econômicas a mais longo prazo. Por conseguinte, e para além do atual consenso econômico, a sua avaliação econômica verdadeira e precisa dependerá em grande medida da profundidade das despesas que estiverem dispostos a fazer, condicionando as respostas tanto para a contenção da pandemia, como para a subsequente recuperação econômica e, por conseguinte, para a recuperação da saúde e da crise econômica.

Embora a ortodoxia econômica imposta em todo o mundo defenda os equilíbrios orçamentais, a verdade é que a análise das medidas dos diferentes países, como é o caso da Reserva Federal e do Tesouro dos EUA, do Tesouro e do Banco de Inglaterra, do bloco da Zona do Euro ou da República Federativa do Brasil, mostra-nos as diferentes sensibilidades que estão para além da ortodoxia atual, uma vez que as diferenças sensíveis das políticas monetárias e dos incentivos fiscais implementados, muitas vezes heterodoxos, nos mostram uma abordagem diferente do fenômeno.

Na União Europeia, cuja zona do euro está sujeita a uma forte camisa de forças financeira através da União Econômica e Monetária, a cláusula de escape do Pacto de Estabilidade e Crescimento foi activada pela primeira vez (assumindo que a estabilização através dos salários e dos preços será absolutamente insuficiente). Isto significa que as regras relativas ao défice público serão flexibilizadas para fazer face às consequências desta pandemia e que serão permitidos auxílios estatais às empresas e aos trabalhadores.

Por seu lado, o Banco Central Europeu anunciou um programa de aquisição líquida de ativos de emergência para a pandemia (PEPP) no valor máximo de 1.350.000 milhões de euros, que servirão para financiar os Estados, e que durará até ao final de Junho de 2021, ou para além desta data, se o Conselho do BCE considerar que a crise ainda não terminou ${ }^{3}$. Além disso, o Conselho da União aprovou em 23 de Abril cerca de 540.000 milhões de euros e a Comissão propôs um Quadro Financeiro Plurianual (QFP) para 2021-2027 de até 1,1 milhão de euros e a criação de um Fundo de Recuperação (Europa da próxima geração de 750 mil milhões de euros) que será provavelmente aprovado num Conselho extraordinário a realizar em Julho. Houve também espaço para a ortodoxia, como o meio trilião de euros posto em circulação através do MEDE.

No entanto, o país que mais claramente parece ter compreendido o mecanismo de produção monetária e se atreveu a tomar a medida mais heterodoxa foi o Reino Unido, que, numa decisão histórica - ainda de natureza temporária - decidiu que o Tesouro britânico deveria ser financiado através de um descoberto com o Banco de

\footnotetext{
${ }^{3}$ EUROPEAN CENTRAL BANK. "Monetary Policy decisions", European Central Bank, 4 jun. 2012. Disponível em:

https://www.ecb.europa.eu/press/pr/date/2020/html/ecb.mp200604 a307d3429c.en.html https://www.ecb.europa.eu/press/pr/date/2020/html/ecb.mp200604 a307d3429c.pt.html
} 
Inglaterra, ou seja, que o Estado britânico deveria ser diretamente financiado pelo seu banco central, evitando o mercado secundário e mostrando a sua falta de receio de causar hiperinflação, como recordou o Financial Times ${ }^{4}$. Todas estas políticas heterodoxas nos questionam sobre as regras de equilíbrio orçamental que tantos países adoptaram.

\section{A CONSTITUCIONALIZAÇÃO DOS SALDOS ORÇAMENTAIS}

\subsection{O caso americano}

Como consequência da sua guerra de independência contra os britânicos, os Estados Unidos iniciaram a sua vida como um país independente com um elevado nível de dívida ${ }^{5}$, tendo de fazer face aos créditos que haviam contraído durante a guerra. O Estado americano teve de decidir não só como enfrentar esta dívida, mas também como transferir uma organização financeira eficiente entre os diferentes Estados e a Federação. Alexander Hamilton, o primeiro Secretário do Tesouro, planejou para o novo país um sistema financeiro moderno que previa a assunção de dívidas estatais pelo governo federal (CHERNOW, 2004, pg. 344-361). Para Hamilton, esta foi não só uma forma de garantir o desenvolvimento do tesouro da União, mas também uma forma de desenvolver a lealdade entre os Estados e a Federação ${ }^{6}$ (HAMILTON, 1789). Embora o plano tenha conseguido, devido à situação financeira catastrófica, levar a Federação a assumir as dívidas dos Estados durante a Guerra da Independência de 1790 e mesmo a de 18127 , em 1840 foi estabelecida uma regra de "no bail out", com excepção do Distrito de Columbia, devido à organização especial do seu governo (HENNING; KESSLER, 2012, p.6). Esta regra foi firmemente respeitada pelo Governo Federal mesmo depois da guerra civil; um acontecimento que pôs à prova a própria relação dos Estados com as suas entidades infra-estatais, pelo que muitos deles reformaram as suas constituições tanto para proibir os salvamentos como para limitar a sua própria emissão de dívida ${ }^{8}$.

${ }^{4}$ GILES, C.; GEORGIADIS, P. "The Bank of England to direct finance the UK's extra spending", Financial Times, 9 abr. 2020. Disponível em: https://www.ft.com/content/664c575b-0f54-44e5ab78-2fd30ef213cb.

${ }^{5}$ No início de 1789, os Estados Unidos acumularam uma dívida de 75 milhões de dólares, uma grande quantia até então. FABER, H. "Once upon a time, a budget surplus", The Nation, 31 dez. 1995. Disponível em: https://www.nytimes.com/1995/12/31/weekinreview/the-nation-once-upona-time-a-budget-surplus.html

6 HAMILTON, A. First Report on Public Credit, 1789. Disponível em: http://presspubs.uchicago.edu/founders/documentos/a1_8_2s5.html. O plano de Hamilton era que a Federação fosse o único credor dos Estados. Ver: RODDEN, J. Hamilton's Paradox: The Promise and Peril of Fiscal Federalism, Cambridge, Cambridge University Press, 2006, 57.

${ }^{7}$ A de 1812, ou a guerra anglo-americana que colocou os Estados Unidos contra o Reino Unido e as suas colônias canadianas.

${ }^{8}$ Ver em: MONKONNEN, E.K. O Estado Local: Public Money and American Cities, Stanford -CA, Stanford University Press, 1995 e INMAN, R.P. "Transfers and Bailouts: Enforcing Local Fiscal 
Atualmente, com a única excepção do Vermont, todos os Estados têm algum tipo de regra de equilíbrio orçamental. Quarenta e quatro Estados têm uma regra constitucional ou estatutária que exige que o Governador respeite a regra orçamental ao elaborar e apresentar o seu projecto de lei do orçamento; quarenta e um dirigem-se ao legislador para este teste de equilíbrio ao aprovar o projeto de lei do orçamento; trinta e sete exigem que o Governador assine um orçamento equilibrado; e quarenta e três próbem o reporte de um défice para o plano orçamental seguinte (anual ou semestral), para além de outras garantias de dívida9 .

No que diz respeito à Federação, houve várias tentativas de introduzir este tipo de regra, coincidindo com acontecimentos traumáticos naquele país. Na década de 1930, durante a presidência de Roosevelt, que impôs a utilização da política fiscal como instrumento anti-cíclico, houve várias tentativas de incluir a regra do equilíbrio orçamental na Constituição dos EUA. Foi o caso do representante do Minnesota, Harold Knutson, ou da Associação Americana de Contribuintes, que propôs consecutivamente uma reforma constitucional para limitar o défice do governo central ${ }^{10}$. No entanto, foi a partir dos anos setenta, após a adopção do paradigma neoliberal que se seguiu à conversão dos EUA num país deficitário ${ }^{11}$, que uma segunda vaga deste tipo de tentativas tomou conta. Numa situação de perda de prosperidade e poder americano, que se traduziu num clima antiWashington, os Estados lançaram uma "revolta orçamental", culpando os défices crescentes por uma ruína econômica que tinha de ser enfrentada através de

Discipline with Lessons from U.S. Federalism", pg. 58 e 65. In: Rodden, J.; Eskelund, G.; Litvack, J. (ed), "Fiscal Decentralization and the Challenge of Hard Budget Constraints", Cambridge, MA: MIT Press, 2003.

${ }^{9}$ Embora se trate de uma questão controversa, esta classificação deve-se a National Association of State Budget Officers (NASBO). HENNING, C.R.; KESSLER, M. "Fiscal federalism: US history for architects of Europe's fiscal union". En: J. Rodden, G. Eskelund, J. Litvack (ed), "Fiscal Decentralization and the Challenge of Hard Budget Constraints", Cambridge, MA: MIT Press, 2003, 11. Pode ser estudada uma análise pormenorizada dos diferentes sistemas com os quais estes regulamentos podem ser contemplados na: HOU, Y.; SMITH, D.L. "A framework for understanding state balanced budget requirement systems: Reexamining distinctive features and an operational definition", Public Budgeting \& Finance, v.26, n. 3, 2006, pg. 22-45. Disponível em: https://onlinelibrary.wiley.com/doi/pdf/10.1111/j.1540-

5850.2006.00853.x?casa_token=Cp7DWI3NadYAAAAA\%3A4uyw0bjdFwkqJeyNTdMOlVo_IB-

ULvUAgRblxxx6HozuorWcLQcAdTrwelBQjtLju2GUxIH_81ZCuM.

${ }^{10}$ BERNSTEIN, R.B.; AGEL, J. Amending America, New York: Time, 1993 e J. SAVAGE, Balanced budgets and American politics, Cornell University Press, 2019. In: GONZÁLEZ, G.M. La constitucionalización de la estabilidad presupuestario en Estados Unidos: lecciones de un debate inacabado, Estudios de Deusto: revista de la Universidad de Deusto, v. 65, n. 2: 247-288,254, 2017

${ }^{11}$ Segundo a tese do Professor Varoufakis, como consequência desta deficiente transformação, que iniciaria uma nova estratégia global na política americana e britânica; ver: VAROUFAKIS, Y. The global minotaur: America, Europe and the future of the global economy, London: Zed Books Ltd., 2015. 
uma limitação constitucional. Depois de Estados como Maryland e Mississippi terem apoiado a reforma constitucional, os dirigentes democratas e republicanos lançaram uma campanha contra a mesma, que conseguiu travar estas iniciativas (MORGAN, 1998, p.421-455). Já nos anos 80 e 90, durante as presidências dos republicanos Ronald Reagan e George H.W. Bush, tiveram lugar duas iniciativas semelhantes: uma do Senador Hatch, apoiada pelo próprio Ronald Reagan, que conduziu à Lei Gramm-Rudman-Hollings de $1985^{12}$ sobre o equilíbrio orçamental e o controlo do défice de emergência; e outra do Presidente Bush na mesma linha (KYVIG, 1994, p.112-120). Estas iniciativas contrastam com o aumento dos défices durante ambas as presidências (o duplo défice comercial e financeiro); paradoxalmente, convidam-nos pelo menos a reconsiderar que tipo de estratégia política apoiou este tipo de iniciativas, que também existiriam durante a presidência de Bill Clinton (KYVIG, 1994, p.112-120).

\subsection{O caso da zona euro}

Ao contrário do que geralmente se pensa, não seria a Alemanha o primeiro país europeu a adoptar uma regra de controlo orçamental, mas sim a França. Após as experiências frustrantes dos primeiros governos da presidência de François Mitterrand, a famosa regra (inconstitucionalizada) de 3\% do PIB seria estabelecida como uma das medidas estrela do chamado "tournant au rigueur", com a qual o Governo francês queria ganhar credibilidade no seu regresso à ortodoxia do mercado. $\mathrm{O}$ aspecto mais marcante da medida, que mais tarde seria transferida do euro para a União Europeia, seria a escolha de um valor (3\%), determinado de forma burocrática ${ }^{13}$, sem qualquer base econômica ${ }^{14}$, e que não respondia à experiência histórica francesa ou europeia de défice (GURUMURTHY, 2016). Seguir-se-ia uma escolha puramente psicológica, a do fascínio humano com certos números (a perfeição e a harmonia de três) (MARSH, 2009).

Como é sabido, a União Econômica e Monetária estabeleceria uma moeda comum (o euro) para os Estados-Membros da União Europeia que adeririam à sua última fase, da qual o Reino Unido e a Dinamarca seriam excluídos, por decisão própria, mediante a assinatura de protocolos específicos. A nova moeda levaria o controlo do défice ao seu nível mais elevado, ao qual estariam sujeitos todos os Estados-Membros da zona euro. Como sabemos, ao assinar o Pacto de Estabilidade

\footnotetext{
12 Esta lei encontrou os seus limites constitucionais relativamente ao executivo em Bowsher vs Synar (478 US 714 - 1986 -) e foi substituída pelo Budget Enforcement Act de 1990, que substituiu os objectivos de défice fixo.

${ }^{13}$ LE PARISIEN, 3\% de déficit: "Le chiffre est né sur un coin de table" GUY ABEILLE l'inventeur du concept des 3\%. Le Parisien, 28 set. 2012. Disponível em: http://www.leparisien.fr/economie/3-dedeficit-le-chiffre-est-ne-sur-un-coin-de-table-28-09-2012-2186743.php

${ }^{14}$ DALLAGO, B. Zona Euro. From distress to deeper integration? In: DALLAGO, B.; MCGOWAN, J. Crises in Europe in the Transatlantic Context: Economic and Political Appraisals. London: Routledge Studies in the Modern World Economy CRC Press, 2015, p. 55.
} 
e Crescimento, os Estados que adoptassem a moeda comum ficariam sujeitos a regras que consistiriam basicamente em permitir um défice orçamental máximo igual a 3\% do rendimento anual do PIB nacional, e 60\% da dívida em relação ao rendimento anual do PIB. Além disso, seria estabelecida uma cláusula de "no bail out", que proibiria um Estado-Membro de assumir as dívidas de outro Estado, impossibilitando os resgates europeus, e proibiria a monetarização da dívida (ou a inexistência de resgate), o que impediria o financiamento directo dos Estados pelo Banco Central Europeu ${ }^{15}$.

Além disso, a maioria dos Estados institucionalizaria o equilíbrio orçamental nos seus sistemas jurídicos, muitos deles nas suas constituições, e alguns em resultado do choque causado pela crise de $2007^{16}$. Seria o caso da Espanha com a reforma discutida do artigo 135ํㅜㄹ da Constituição (SANCHÉZ BARRILAO, 2013, p. 679-712), que incluiria estas regras de controlo orçamental e da dívida, mas também de Estados como a França (no seu artigo $34^{\circ}$ constitucional), a Itália, a Polónia, a Eslovénia ou a Alemanha.

\subsection{O caso do Brasil}

A República Federativa do Brasil não introduziria políticas de austeridade nas finanças públicas até 1987, nas vésperas da promulgação da Constituição de 1988, no chamado Programa de Estabilização Macroeconômica. Pelo contrário, o Banco Central do país financiaria o Tesouro Público Federal através de diferentes mecanismos, um realmente curioso, o de uma "conta de movimento" em nome do Tesouro Nacional no Banco do Brasil, que era equilibrada diariamente pelo Banco Central do Brasil ${ }^{17}$.

A grande consagração das regras de equilíbrio financeiro viria com a Lei Complementar n. ${ }^{-}$101, de 4 de Maio de 2000, que estabeleceria as regras de financiamento público da responsabilidade da gestão fiscal e outras disposições ${ }^{18}$ que desenvolveriam os pontos I e V do artigo $163^{\circ}$ da Constituição Brasileira ${ }^{19}$. Esta lei estabeleceria os limites do endividamento da Federação, das Unidades Federais e dos Governos Municipais, para além de outras regras relacionadas com o pessoal e as despesas eleitorais (NÓBREGA, 2016, p. 40-41). Mais tarde, o Brasil mostraria a sua forte fé no equilíbrio orçamental, estabelecendo o crime de responsabilidade

\footnotetext{
${ }^{15}$ Artigo $103^{\circ}$ do TCE.

16 Ver o relato dos acontecimentos que levaram o Presidente do Governo espanhol a concordar com a reforma do artigo $135^{\circ}$ da Constituição espanhola, o que seria feito de uma forma definida por "expressa" (RODRIGUEZ ZAPATERO, 2013).

${ }^{17} \mathrm{E}$ outros mecanismos como o estabelecimento de créditos, a gestão directa de certos impostos federais, como os impostos de exportação e as operações financeiras que não seriam contabilizadas nos orçamentos federais para os constituir como reservas monetárias. (NÓBREGA, 2016)

18 Lei Complementar $\mathrm{n}^{\mathrm{o}} 101$, de 4 de maio de 2000. Disponível em: http://www.planalto.gov.br/ccivil_03/leis/lcp/lcp101.htm.

${ }^{19}$ Art. 163, (Capítulo II Das finanças públicas). Disponível em: http://www.planalto.gov.br/ccivil_03/Constituicao/Constituicao.htm\#titulovicapituloii.
} 
fiscal, através da Lei no 1028, de 19 de Outubro de 2000, que alargaria os crimes de responsabilidade estabelecidos na Lei no 1079, de 10 de Abril de 1950. Assim, os novos pontos 5 a 12 do artigo $10^{\circ}$ da Lei $\mathrm{n}^{\mathrm{o}} 1079$ tipificariam as condutas contrárias à Lei da Responsabilidade Fiscal, relativas à execução do orçamento e à gestão das finanças públicas, que seriam punidas com prisão, perda de direitos políticos e que seriam cumulativas com sanções administrativas (NÓBREGA, 2016, p.40-41).

Aprovada em 16 de Dezembro de 2016, a introdução de um limite federal de despesas públicas seria objeto da alteração constitucional 95/2016, que instituiria um novo regime fiscal válido até 2036.

A proposta brasileira de aplicação do limite máximo da despesa pública federal, que é objeto do PEC 241/55, foi aprovada em 16 de Dezembro de 2016, tendo sido consolidada na Emenda Constitucional no 95, que instituiu um novo regime fiscal. A reforma estabelece limites anuais individualizados para as despesas primárias de cada um dos ramos do Governo (Executivo, Judicial e Legislativo), bem como do Ministério Público e do Gabinete do Provedor de Justiça ${ }^{20}$. A medida restringe significativamente o crescimento das despesas obrigatórias (despesas fiscais e da segurança social), em especial as dos funcionários públicos ${ }^{21}$. $\mathrm{O}$ regime estará em vigor durante os próximos vinte anos, sendo assim válido até 2036. Embora a meio do período de validade, poderá ser revisto, desde que o cenário económico se revele favorável; com algumas excepções de aumentos de limites de crédito extraordinários, despesas eleitorais, contribuições para aumentos de capital de empresas estatais não dependentes e transferências ligadas às Unidades Federais e Municipais, que não poderão ser revistas ${ }^{22}$.

Como é sabido, a reforma foi objeto de Ações Diretas de Inconstitucionalidade (ADI) de números 5633/DF - de autoria da Associação Nacional dos Magistrados do Brasil - e 5658/DF - proposta pelo Partido Democrata do Trabalho - resolvida negativamente pelo Supremo Tribunal Federal no MS 34.448-MC/DF².

\footnotetext{
${ }^{20}$ SARAIVA, A.M.; DE CASTRO PEREIRA, R.A.; GOMES, J.W.; BEZERRA, A.R; LÚCIO, F.G.C. Reformas Fiscais no Brasil: uma análise da EC 95/2016" (Teto dos Gastos). In: XX Encontro de Economia da Região Sul, 2017, Porto Alegre. Anais do XX Encontro de Economia da Região Sul. Rio de Janeiro: Associação Nacional dos Centros de Pós-Graduação em Economia (ANPEC), 13, 4. ${ }^{21}$ SARAIVA, A.M.; DE CASTRO PEREIRA, R.A.; GOMES, J.W.; BEZERRA, A.R; LÚCIO, F.G.C. "Reformas Fiscais no Brasil: uma análise da EC 95/2016" (Teto dos Gastos), XX Encontro de Economia da Região Sul, 2017, Porto Alegre. Anais do XX Encontro de Economia da Região Sul. Rio de Janeiro: Associação Nacional dos Centros de Pós-Graduação em Economia (ANPEC), 3, 8.

22 SARAIVA, A.M.; DE CASTRO PEREIRA, R.A.; GOMES, J.W.; BEZERRA, A.R; LÚCIO, F.G.C. "Reformas Fiscais no Brasil: uma análise da EC 95/2016" (Teto dos Gastos). XX Encontro de Economia da Região Sul, 2017, Porto Alegre. Anais do XX Encontro de Economia da Região Sul. Rio de Janeiro: Associação Nacional dos Centros de Pós-Graduação em Economia (ANPEC)

${ }^{23}$ Para uma forte crítica a esta reforma constitucional, ver: SEGUNDO, H. DE B. M. Emenda Constitucional 95/2016 e o teto dos gastos públicos. Revista Controle - Doutrina e Artigos, v. 15, n. 2, 22-40, 18 mai. 2018.
} 


\section{O EQUILÍbRIO ORÇAMENTAL: A SUA NARRATIVA FACE À REALIDADE DA CRISE DE 2007}

\subsection{As narrativas sobre o equilíbrio orçamental}

As diferentes experiências de constitucionalização e o desenvolvimento do equilíbrio financeiro dos Estados levariam ao desenvolvimento de uma série de narrativas que se baseariam na nova ortodoxia econômica.

Assim, no caso dos Estados Unidos, isso seria construído com base no fato de o objetivo da constitucionalização do equilíbrio orçamental, representado pela responsabilidade dos Estados, estar à espera de ser finalmente alcançado a nível federal. Não é difícil supor que isso se basearia facilmente na tradicional desconfiança em relação ao Estado e, em particular, ao poder de uma Washington dominada por burocratas liberais, que Hollywood também nos tem podido mostrar.

A União Europeia desenvolveria a sua própria versão com base nos seus próprios preconceitos e apresentaria duas Europas, uma eficaz e disciplinada formada pelos países excedentários e outra dos países periféricos (que seriam batizados pela sigla pejorativa de PIGS), que precisariam de limites legais e mesmo constitucionais devido à sua tendência para o endividamento e para a despesa pública.

No Brasil, a sua situação seria comparada à dos países que passariam a ser conhecidos como "euro fraco" (SCUDELER, 2018, pg. 32), com os quais são comparados, considerando "a consolidação das contas públicas" como uma condição necessária para o desenvolvimento econômico do país (SALTO; ALMEIDA, 2016, p. 25).

\subsection{A análise dos fluxos financeiros, especialmente em relação à crise de 2007}

Uma análise dos fluxos financeiros mostra-nos como estas narrativas estão bastante afastadas da realidade dos fatos.

Com o peso da despesa pública estadual e subestatal representando $40 \%$ da despesa pública (HENNING; KESSLER, 2012, pg. 14), a análise dos fluxos financeiros do gigante americano mostra como, na realidade, as restrições orçamentais dos estados americanos nada mais fazem do que aumentar o papel do governo federal na estabilização macroeconômica do país, ou seja, a inflexibilidade financeira dos estados é possível graças à flexibilidade federal (HENNING; KESSLER, 2012, pg. 20), que limita a influência pró-cíclica dos estados (devido precisamente às suas restrições de gastos) durante as recessões (HINES, 2010). Por exemplo, em 2010, de acordo com o Gabinete do Orçamento do Congresso (CBO), $75 \%$ das subvenções do pacote de estímulo aos Estados foram utilizadas para financiar défices estatais e não novos projetos (HENNING; KESSLER, 2012, pg. 15). Isto para além do facto de os Estados Unidos da América serem um dos países mais deficitários do mundo desde os anos 70. 
Pela sua parte, a análise do funcionamento da zona euro mostra como a construção do euro sofreria de grandes fissuras durante a crise de 2007, que seriam resolvidas por uma política certamente heterodoxa em relação aos Tratados, o que, de alguma forma, não torna tão novas as medidas tomadas pelo Conselho do BCE contra a pandemia de Covid 19. O programa responderia às intenções anunciadas pelo senhor deputado. O programa responderia às intenções anunciadas por Draghi, Governador do Banco Central Europeu, durante o Verão de 2012, que declararia que faria tudo o que fosse necessário para salvar o euro (dos especuladores nos mercados em que os Estados devem financiar-se de acordo com a concepção jurídica da União Monetária ${ }^{24}$ e que envolvia um longo programa de aquisição de activos públicos e privados denominado expansão quantitativa, e que apesar do seu elevado grau de conflito com o espartilho definido pelos Tratados, seria considerado conforme ao direito da União pelo Tribunal de Justiça Europeu no seu acórdão de 16 de Junho de 2015 (embora contestado pelo Tribunal Federal alemão no seu acórdão de 5 de Junho deste ano e que criticaria a aquisição de obrigações pelo Bundesbank excluiria expressamente a sua decisão sobre a situação da Covid 19) ${ }^{25}$.

Mais em consonância com a doutrina econômica ortodoxa, seria igualmente criado um mecanismo de assistência temporária aos Estados, como o Mecanismo Europeu de Estabilização Financeira (EFSM), bem como o MEDE (Mecanismo Europeu de Estabilidade) definitivo, que está disposto a conceder empréstimos garantidos pelos Estados-Membros da zona euro (na qualidade de accionistas) aos Estados que necessitam de assistência. Um mecanismo, aliás, criado com um tal grau de "engenharia jurídica" que denota uma obsessão em manter o aspecto do bom funcionamento do espartilho.

Quanto ao caso brasileiro e sob o nome algo pejorativo utilizado pela imprensa de "contabilidade criativa", a crise de 2007 seria combatida no Brasil com medidas para aumentar a despesa pública e o crédito através, por exemplo, do Banco Nacional de Desenvolvimento Econômico e Social, que - paradoxalmente - teve um bom desempenho e permitiria anunciar excedentes orçamentais primários, graças ao crescimento do próprio produto interno; entre 2007 e 2012 (NÓBREGA, 2016, pg. 44;47).

\section{FINANÇAS FUNCIONAIS FACE À CRISE DA COVID 19}

A 4 de Junho, a televisão britânica Channel 4 realizou uma entrevista com a economista Stephanie Kelton, autora do livro "The deficit myth: modern monetary

\footnotetext{
${ }^{24}$ Esta afirmação é melhor compreendida a seguir, se se entender que o BCE não é o "desembarcador de último recurso" que é o foco da função de qualquer banco central.

${ }^{25}$ BVerfG, Acórdão do Segundo Senado de 05 de Maio de 2020 - 2 BvR 859/15 -, par. 1-237. Disponível em: http://www.bverfg.de/e/rs20200505_2bvr085915en.html.
} 
theory and the birth of the people's economy"26. O conselheiro do Senador Bernie Sanders durante a sua campanha para as eleições presidenciais democráticas e conselheiro do atual candidato Joe Biden respondeu que era necessário um aumento significativo da despesa pública, sob a forma de um grande New Deal Verde, sem que o aumento dos défices tivesse de constituir um grande problema para a economia dos EUA. Para confrontar as suas opiniões, o historiador Niall Ferguson foi entrevistado ao mesmo tempo, chegando ao ponto de dizer que os Estados Unidos não deveriam abandonar a via do equilíbrio orçamental que o tinha caracterizado. Esta afirmação foi imediatamente respondida pelo economista, alegando que se tratava de dados absolutamente falsos e contrastados (os Estados Unidos são um país com um grande défice fiscal e orçamental no mundo desde os anos setenta) ${ }^{27}$.

Em contrapartida, as grandes potências econômicas mundiais, como a China, o Reino Unido, o Japão e os Estados Unidos, encontram-se entre os países com maior percentagem de défice orçamental ou de dívida pública em relação ao seu produto interno bruto $^{28}$. Precisamente por esta razão, é impressionante como a estabilidade orçamental se tornou mitigada, mesmo num país com um enorme desequilíbrio orçamental e de dívida como o gigante americano. Um certo consenso, salientado pelo Prémio Nobel da Economia Paul Samuelson, que não hesita em salientar o seu carácter mitológico, desempenhando um papel semelhante ao desempenhado pelas religiões antigas, assustando as pessoas em prol de objectivos mais nobres (WRAY, 2015, pg.198). Longe disso está o paradigma keynesiano dominante dos anos 30 a 70, no qual o próprio Millton Friedman assinalou que o governo deveria procurar equilibrar o orçamento, uma vez obtido o pleno emprego, mas deveria

\footnotetext{
${ }^{26}$ KELTON, S. The deficit myth: modern monetary theory and the birth of the people's economy. Hachette UK, 2020.

${ }^{27}$ FREI, M. Economist Stephanie Kelton on US unemployment crisis: "The only game in town is the federal government". 4 News - Channel 4, 4 jun. 2020. Disponível em: https://www.channel4.com/news/economist-stephanie-kelton-on-us-unemployment-crisis-theonly-game-in-town-is-the-federal-government

${ }^{28}$ Por exemplo, o Reino Unido e os Estados Unidos da América não poderiam fazer parte da zona euro. Em 2019, o Reino Unido cumpriu a regra do défice pelo terceiro ano consecutivo, mas não cobre a regra da dívida (situava-se em 69,9\% do PIB em Março e $84 \%$ em Setembro, muito acima dos $60 \%$ exigidos pelo Tratado de Maastricht). Ver: UK GOVERNMENT DEBT AND DEFICIT: MARCH 2019, Office of National Statistics, 2019. Disponível em: https://www.ons.gov.uk/economy/governmentpublicsectorandtaxes/publicspending/bulletins/u kgovernmentdebtanddeficitforeurostatmaast/march2019 e UK GOVERNMENT DEBT AND DEFICIT: SEPTEMBER 2019, Office of National Statistics, 2019.

https://www.ons.gov.uk/economy/governmentpublicsectorandtaxes/publicspending/bulletins/u kgovernmentdebtanddeficitforeurostatmaast/september2019.

A nível internacional pode ver as estatísticas fornecidas pela Central Intelligence Agency na sua Web, "The World Factbook". CENTRAL INTELLIGENCE AGENCY. Disponível em: https://www.cia.gov/library/publications/the-world-factbook/fields/226rank.html.
} 
incorrer em défices em tempos de recessão e em excedentes em tempos de expansão económica (FRIEDMAN, 1995, pg.345-365).

Apesar deste consenso, em 2019 o economista Randall Wray declararia na muito poderosa Comissão de Orçamento do Congresso dos Estados Unidos da América ${ }^{29}$ relativamente aos défices e à austeridade:

Podemos tentar reduzir os défices através de medidas de austeridade, caso em que a resposta da economia pode acabar por aumentar o défice, na medida em que abranda o crescimento". Ou podemos optar por impulsionar o crescimento através de políticas fiscais pró-ativas que poderão então aumentar as receitas fiscais e reduzir as despesas de transferência, reduzindo assim o défice. Uma vez que o rácio do défice ou da dívida não é um bom indicador da actividade econômica, não deve, em caso algum, ser o foco da definição de políticas ${ }^{30}$. (WRAY, 2019)

29 "Comissão dos Orçamentos da Câmara".

30 "Podemos tentar reduzir os défices através de medidas de austeridade, caso em que a resposta da economia pode acabar por aumentar o défice, na medida em que abranda o crescimento". Ou podemos optar por impulsionar o crescimento através de políticas fiscais pró-activas que poderão então aumentar as receitas fiscais e reduzir as despesas de transferência, diminuindo assim o défice". Uma vez que o défice ou o rácio da dívida não é um bom indicador do desempenho económico, não deve, em caso algum, ser o centro das decisões políticas". WRAY, L.R. Statement by L Randall Wray, Congressional Testimony: Reexamining the Economic Costs of Debt. Audição perante a Comissão do Orçamento da Câmara, 20 nov. 2019, 21. Disponível em:

https://budget.house.gov/sites/democrats.budget.house.gov/files/documents/Wray_Testimony.p df. Também está disponível a gravação da aparição do especialista perante o Comitê do Congresso dos Estados Unidos: https://budget.house.gov/legislation/hearings/reexamining-economic-costsdebt.

A resposta a esta incursão de uma nova perspectiva econômica-constitucional sobre os défices das instituições dos Estados Unidos por parte do Partido Democrata seria quase inquisitorial: cinco senadores promoveriam a condenação da Teoria Moderna no Senado como uma ameaça à economia americana. Apesar do apoio de um grande número de economistas neoliberais, a medida (de natureza não vinculativa (uma "resolução não vinculativa") e disfarçada sob o eufemismo do "reconhecimento do direito de condenar a Teoria Monetária Moderna") seria criticada não só pelos seguidores da corrente, mas por uma grande parte da Academia e mesmo por publicações econômicas não propriamente heterodoxas como a Forbes. Ver: Senate Resolution 182 Recognizing the duty of the Senate to condemn Modern Monetary Theory and Recognizing Modern Monetary Theory would lead to higher deficits and higher inflation. Congressional Record Senate, May 1, 2019.2 Disponível em: https://www.perdue.senate.gov/imo/media/doc/MMT\%20Resolution.pdf H.T .HARVEY, J. T. The Senate Resolution To Condemn MMT: Here are some better candidates for condemnation. Forbes, 3 mai. 2019. Disponível em: https://www.forbes.com/sites/johntharvey/2019/05/03/the-senatemotion-to-condemn-mmt-here-are-some-better-suggestions-for-condemnation/\#3a6c777831cb; ou um artigo que o colocaria mais na defesa do Senador Alexandro Ocasio -Cortez das propostas desta abordagem econômica. DIMITRIEVA, K. "Senate Has a Duty to Denounce MMT, 
Propor uma visão alternativa, que ele próprio encarnou:

(...) o que aqui discuti é largamente descritivo. A Teoria Monetária Moderna permite-nos olhar para a economia através de uma lente diferente. Enquanto economistas e decisores políticos podem defender a redução dos défices e da dívida pública, a Teoria Monetária Moderna adverte que o que podemos estar a reduzir é o crescimento económico, bem como os excedentes do setor privado e a riqueza financeira líquida (WRAY, 2019) ${ }^{31}$.

Os políticos de ambos os lados do espectro ideológico americano também têm flertado com estas abordagens. Seria o caso do influente senador republicano Mario Rubio $^{32}$, que, num relatório intitulado American Investment in the 21st Century on domestic investment $(\mathrm{O}$ Investimento Americano no Século XXI sobre o Investimento Interno), teria em conta muitas destas ideias, com citações específicas de economistas membros desta corrente econômica como Pavlina Tcherneva, que ${ }^{33}$ obviamente - a imprensa especializada ecoaria, não sem alguma morbidez. ${ }^{34}$

Na zona euro, a intensificação das contradições na sequência da crise de 2007, causadas pela deflação da zona euro, permitiria vislumbrar heterodoxias muito semelhantes, como a que viria do Governador do Banco Central Europeu, o senhor Draghi, que, em 23 de setembro de 2019, durante a sua comparência na Comissão

Republicans Say in Resolution", Bloomberg, 3 mai. 2019. Disponível em: https://www.bloomberg.com/news/articles/2019-05-03/senate-republicans-mmt.

31 "Embora a MMT tenha um conjunto de prescrições políticas para alcançar o pleno emprego e a estabilidade de preços, o que aqui discuti é em grande medida descritivo. A MMT permite-nos olhar para a economia através de uma lente diferente. Enquanto economistas e decisores políticos podem defender a redução dos défices e da dívida pública, a MMT adverte que o que podemos estar a reduzir é o crescimento económico, bem como os excedentes do sector privado e a riqueza financeira líquida". WRAY, L.R. Statement by L Randall Wray, Congressional Testimony: Reexamining the Economic Costs of Debt. Audição perante a Comissão do Orçamento da Câmara, 20 nov. 2019, 21. Disponível em: https://budget.house.gov/sites/democrats.budget.house.gov/files/documents/Wray_Testimony.p df. P. 20.

32 Senador republicano pelo Estado da Florida e Chairman of the Senate Committee on Small Business and Entrepreneurship.

${ }^{33}$ RUBIO, M. American Investment in the 21th century. Senado dos EUA, 15 mai. 2019. Disponível em: https://www.rubio.senate.gov/public/index.cfm/2019/5/rubio-releases-report-on-domesticinvestment.

https://www.rubio.senate.gov/public/_cache/files/9f25139a-6039-465a-9cf1feb5567aebb7/4526E9620A9A7DB74267ABEA5881022F.5.15.2019.-final-project-report-americaninvestment.pdf.

${ }^{34}$ HOLLAND, B. Marco Rubio put outs a paper citing a obscuring left wing economists. Bloomberg, 16 mai. 2019. Disponível em: https:/www.bloomberg.com/news/articles/2019-05-16/asrepublicans-trash-mmt-marco-rubio-seems-to-find-it-useful. 
dos Assuntos Económicos e Monetários, salientaria, sobre como lidar com riscos como as alterações climáticas e a desigualdade, que "novas ideias sobre política monetária, como a MMT (Teoria Monetária Moderna) e trabalhos recentes apresentados por vários autores, incluindo o Professor Fischer e outros, sugerem diferentes formas de canalizar dinheiro para a economia" (DRAGHI, 2019); salientando a natureza política da questão ${ }^{35}$.

Estes conceitos têm precedentes importantes, como o breve, mas interessante artigo que, em 1946, Beardsley Ruml, Presidente da Reserva Federal de Nova Iorque escreveu, que começou com uma reflexão profunda e perturbadora: "Esta parece ser uma pergunta simples, mas, como é o caso de perguntas simples, a resposta óbvia é suscetível de ser superficial. A resposta óbvia é, evidentemente, que os impostos proporcionam as receitas de que o governo necessita para pagar as suas contas" (RUML, 1946, p. 35-39). Nesse artigo, o Presidente abordou uma questão delicada com grande previdência, o verdadeiro papel da política fiscal, mostrando o seu profundo conhecimento da natureza do dinheiro. No parágrafo seguinte, abordou directamente a questão do equilíbrio orçamental, observando que a história financeira dos últimos anos mostrou que os países podiam pagar as suas contas, apesar de as suas receitas fiscais não satisfazerem as suas despesas (RUML, 1946, pg. 35-39). A sua reflexão surgiu, disse, de mudanças ocorridas nos últimos vinte e cinco anos que alteraram a posição do Estado (referia-se ao Estado Federal, não aos Estados e às autoridades locais) no que diz respeito ao financiamento. Estas alterações foram "uma vasta experiência nova na gestão dos bancos centrais" e "a eliminação, para fins domésticos, da convertibilidade da moeda em ouro". O artigo explicava o verdadeiro papel que os impostos federais deveriam ter, rejeitando a sua visão como recurso e reivindicando a sua natureza

\footnotetext{
35 "(...) Será esta, como disse, a melhor forma de atribuir liquidez se tiver em mente objectivos como as alterações climáticas ou a redução das desigualdades de uma forma mais enérgica e eficaz? Bem, provavelmente não. Provavelmente, há diferentes formas de o fazer. De facto, algumas das novas ideias sobre política monetária - como a MMT (Teoria Monetária Moderna) e trabalhos recentes apresentados por vários autores, incluindo o Professor Fischer e outros - sugerem diferentes formas de canalizar dinheiro para a economia. Estas são, objectivamente, ideias bastante novas. Não foram discutidas pelo Conselho do BCE e, por isso, devemos analisá-las. Mas também não foram testadas e, quando as analisamos de perto, damo-nos conta de que a tarefa de distribuir dinheiro para um ou outro assunto é tipicamente uma tarefa fiscal. Trata-se de uma decisão governamental. Não é uma decisão do banco central. E certamente não quereria que o banco central decidisse quem deve receber o dinheiro". DRAGHI, M. Committee on economic and monetary affairs monetary dialogue with Mario Draghi, President of the European Central Bank (pursuant to article 284(3) TFEU) Brussels, Monday, 23 september 2019. Disponível em: https://www.ecb.europa.eu/press/key/date/2019/html/ecb.sp190923_transcript $\sim$ dc7717fa5.mu.p df. Declarações que seriam amplamente divulgadas pela imprensa especializada. O'BRIEN, F. Draghi says ECB shoud examine new ideas like MMT, Bloomberg, 23 set. 2019. Disponível em: https://www.bloomberg.com/news/articles/2019-09-23/draghi-says-ecb-should-examine-newideas-like-mmt.
} 
como instrumento ${ }^{36}$, colocando sobre a mesa o que é conhecido como financiamento funcional.

Para compreender a importância de tais palavras, há que recordar que o próprio Presidente Obama, durante 2010, assegurou frequentemente que o Governo dos Estados Unidos estava "a ficar sem dinheiro" (WRAY, 2015, p. 197). Uma declaração que teria de ser corrigida pelo Sr. Bernanke, Presidente da Reserva Federal, quando esclareceu que a Reserva Federal não poderia ficar sem dinheiro, uma vez que poderia sempre conceder crédito às reservas bancárias, datilografando-o (WRAY, 2015, p. 198). Algo que os britânicos acabam de demonstrar claramente com a decisão do Banco de Inglaterra de financiar o seu Tesouro.

Assim, a ideia de que "não há alternativa" que impulsionará inexoravelmente as políticas de combate à pandemia e de recuperação económica, pelo menos, tem a sua origem nos países centrais do capitalismo.

Em 12 de Abril de 1959, em Indianapolis, o Presidente John Fitzgerald Kennedy referiu que, em chinês mandarim, a palavra crise é composta por dois caracteres Wei e Ji, em que o primeiro significa perigo e o segundo, oportunidade ${ }^{37}$. Sem dúvida, a pandemia que infelizmente estamos a viver pode tornar-se um "ponto de viragem" 38 , levando a uma grande mudança na forma como conduzimos a economia, particularmente no que diz respeito aos equilíbrios das finanças públicas, quer através de reformas constitucionais formais, quer através de alterações nas "declarações constitucionais" que as interpretam. O tempo o dirá.

\section{REFERENCIAS}

BERNSTEIN, R. B.; AGEL, J. Amending America. New York: Time, 1993

\section{SAVAGE, J. Balanced budgets and American politics. New York: Cornell University Press, 2019.}

\footnotetext{
36 "Os impostos federais podem ser feitos para servir quatro objectivos principais de carácter social e económico. Estes objectivos são: 1. como instrumento de política fiscal para ajudar a estabilizar o poder de compra do dólar; 2. expressar política pública na distribuição da riqueza e do rendimento, como no caso dos impostos progressivos sobre o rendimento e o património; 3. "Os impostos federais podem ser feitos para servir quatro objectivos sociais e económicos principais. Estes objectivos são: 1. como instrumento de política fiscal para ajudar a estabilizar o poder de compra do dólar; 2. expressar políticas públicas na distribuição da riqueza e do rendimento, tais como impostos progressivos sobre o rendimento e a riqueza; 3. expressar políticas públicas subsidiando ou penalizando várias indústrias e grupos económicos; 4. isolar e avaliar directamente os custos de certos benefícios nacionais, tais como as auto-estradas e a segurança social"]. (a tradução é nossa). RUML, B. Taxes for revenue are obsolete. American Affairs v.8, n.1, 1946, p. 36."

${ }^{37}$ Esta versão tem sido discutida por alguns linguistas. Ver: MAIR, V.H. danger+oportunity= crisis. How a minsunderstanding about Chinese characters has led many lost. Pinyin.Info, set. 2009.

38 "A palha que quebra as costas do camelo."
} 
GONZÁLEZ, G.M. La constitucionalización de la estabilidad presupuestaria en Estados Unidos: lecciones de un debate inacabado. Estudios de Deusto: revista de la Universidad de Deusto, v. 65, n. 2: 247-288. Disponível em: http://revistaestudios.revistas.deusto.es/article/view/1381/1681

CENTRAL INTELLIGENCE AGENCY. The World Factbook. Disponível em: https:/www.cia.gov/library/publications/the-world-factbook/fields/226rank.html.

CHERNOW, R. Alexander Hamilton. New York: Penguin Press, 2004, p. 344-361.

DALLAGO, B. Zona Euro. From distress to deeper integration? In: DALLAGO, B.; MCGOWAN, J. Crises in Europe in the Transatlantic Context: Economic and Political Appraisals. Londres: Routledge Studies in the Modern World Economy CRC Press, 2015.

DIMITRIEVA, K. Senate Has a Duty to Denounce MMT, Republicans Say in Resolution. Bloomberg, 3 mai. 2019. Disponível em: https://www.bloomberg.com/news/articles/2019-05-03/senate-republicans-mmt

DRAGHI, M. Committee on economic and monetary affairs monetary dialogue with Mario Draghi, President of the European Central Bank (pursuant to article 284(3) TFEU). Brussels, Monday, 23 sept. 2019. Disponível em: https://www.ecb.europa.eu/press/key/date/2019/html/ecb.sp190923_transcript $8 d$ c7717fa5.mu.pdf.

EUROPEAN CENTRAL BANK. Monetary Policy decisions. European Central Bank, 4 jun. 2012.

https://www.ecb.europa.eu/press/pr/date/2020/html/ecb.mp200604 a307d3429c.e n.html

FABER, H. Once upon a time, a budget surplus. The Nation, 31 dez. 1995. https://www.nytimes.com/1995/12/31/weekinreview/the-nation-once-upon-atime-a-budget-surplus.html.

FREI, M. Economist Stephanie Kelton on US unemployment crisis: 'The only game in town is the federal government'. 4 News - Channel 4, 4 jun. 2020. Disponível em: https://www.channel4.com/news/economist-stephanie-kelton-onus-unemployment-crisis-the-only-game-in-town-is-the-federal-government 
FRIEDMAN, M. A monetary and fiscal framework for economic stability. In: ESTRIN, S., MARIN, A. (eds.) Essential Readings in Economics, London: Palgrave, 1995, p. 345-365.

FUKUYAMA, F. The end of history and last man. London: Penguin, 1992.

GALLIGAN, D.J.; VERSTEEG, M. Theoretical Perspectives on the Social and Political Foundations of Constitutions. In: GALLIGAN, D.J.; VERSTEEG, M. (eds.), Social and political foundations of Constitutions, Cambridge, UK: Cambridge University Press, 2013, 8-22.

GURUMURTHY, S. For a paradigm shift in fiscal deficit. The Hindu, 7 mar. 2016.

HAMILTON, A. First Report on Public Credit, 1789. http://presspubs.uchicago.edu/founders/documents/a1_8_2s5.html.

HARVEY, J.T. The Senate Resolution To Condemn MMT: Here are some better candidates for condemnation. Forbes, 3 mai. 2019.

https://www.forbes.com/sites/johntharvey/2019/05/03/the-senate-motion-tocondemn-mmt-here-are-some-better-suggestions-forcondemnation/\#3a6c777831cb.

HENNING, C.R.; KESSLER, M. "Fiscal federalism: US history for architects of Europe's fiscal union". Peterson Institute for International Economics Working Paper, 2012-1, 2012, p.6. Disponível em:

https://papers.ssrn.com/sol3/papers.cfm?abstract_id=1982709.

HENNING, C.R.; KESSLER, M. Fiscal federalism: US history for architects of Europe's fiscal union. Peterson Institute for International Economics Working Paper 2012-1, 2012

HINES, J.R. "State Fiscal Policies and Transitory Income Fluctuations", Brookings Papers on Economic Activity, 2010, 313-37. Washington: Brookings Institution.

HOLLAND, B. "Marco Rubio put outs a paper citing a obscuring left wing economists", Bloomberg, 16 de mayo de 2019.

https://www.bloomberg.com/news/articles/2019-05-16/as-republicans-trash-mmtmarco-rubio-seems-to-find-it-useful.

HOU, Y.; SMITH, D. L. A framework for understanding state balanced budget requirement systems: Reexamining distinctive features and an operational 
definition, Public Budgeting \& Finance, v.26, n. 3, 2006. Disponível em:

https://onlinelibrary.wiley.com/doi/pdf/10.1111/j.1540-

5850.2006.00853.x?casa_token=Cp7DWI3NadYAAAAA\%3A4uyw0bjdFwkqJeyNT

dMOlVo_IB-ULvUAgRblxxx6HozuorWcLQcAdTrwelBQjtLju2GUxIH_81ZCuM.

INMAN, Robert. Transfers and Bailouts: Enforcing Local Fiscal Discipline with Lessons from U.S. Federalism. In: RODDEN, J.; ESKELUND, G.; LITVACK, J (eds.). Fiscal Decentralization and the Challenge of Hard Budget Constraints, Cambridge, MA: MIT Press, 2003, p. 58-65.

KELTON, S. The deficit myth: modern monetary theory and the birth of the people's economy. New York: PublicAffairs, 2020.

LE PARISIEN, “3\% de déficit: «Le chiffre est né sur un coin de table» GUY ABEILLE l'inventeur du concept des 3\%, Le Parisien, 28 septiembre, 2012. http://www.leparisien.fr/economie/3-de-deficit-le-chiffre-est-ne-sur-un-coin-detable-28-09-2012-2186743.php.

MAIR, V.H. $<<$ danger+opportunity= crisis $>>$ How a minsunderstanding about

Chinese characters has led many astray. Pinyin.Info, set. 2009.

MARSH, D. The Euro, the politics of the new global currency. London: Yale University Press, 2009.

MONKONNEN, E.K. The Local State: Public Money and American Cities, Stanford -CA: Stanford University Press, 1995

MORGAN, I. Unconventional politics: The campaign for a balanced-budget amendment constitutional convention in the 1970s. Journal of American Studies, v. 32, n.3, 1998, 421-445.

NÓBREGA, M. D. Construção e desmonte das instituições fiscais. In: SALTO, F; ALMEIDA, M. (org.) Finanças Públicas: da contabilidade critativa ao resgate da credibilidade. Rio de Janeiro: Record, 2016, p. 31- 32

O'BRIEN, F. Draghi says ECB shoud examine new ideas like MMT. Bloomberg, 23 set. 2019. Disponível em: https://www.bloomberg.com/news/articles/2019-0923/draghi-says-ecb-should-examine-new-ideas-like-mmt.

RODDEN, J. Hamilton's Paradox: The Promise and Peril of Fiscal Federalism, Cambridge, UK: Cambridge University Press, 2006, 57. 
RODRIGUEZ ZAPATERO, J.L. El dilema: 600 días de vértigo. España: Grupo Planeta (GBS), 2013.

RUBIO, M. American Investment in the 21th century. US Senate, 15 mai. 2019. Disponível em: https://www.rubio.senate.gov/public/index.cfm/2019/5/rubioreleases-report-on-domestic-investment.

https://www.rubio.senate.gov/public/_cache/files/9f25139a-6039-465a-9cf1feb5567aebb7/4526E9620A9A7DB74267ABEA5881022F.5.15.2019.-final-projectreport-american-investment.pdf.

RUML, B. Taxes for revenue are obsolete. American Affairs v.8, n.1, 1946

SALTO, F; ALMEIDA, M. (org.) Finanças Públicas: da contabilidade critativa ao resgate da credibilidade, Rio de Janeiro: Record, 2016

SÁNCHEZ BARRILAO, J.F. "La crisis de la deuda soberana y la reforma del artículo 135 de la Constitución española". Boletín mexicano de derecho comparado, v. 46, n. 137, 2013, p. 679-712. Disponível em: https://www.sciencedirect.com/science/article/pii/S0041863313711463

SARAIVA, A.M.; DE CASTRO PEREIRA, R.A.; GOMES, J.W.; BEZERRA, A.R.; LÚCIO, F.G.C. Reformas Fiscais no Brasil: uma análise da EC 95/2016 (Teto dos Gastos). XX Encontro de Economia da Região Sul, 2017, Porto Alegre. Anais do XX Encontro de Economia da Região Sul. Rio de Janeiro: Associação Nacional dos Centros de Pós-Graduação em Economia (ANPEC)

SCUDELER, M. Entre a estabilidade e crescimento e ordem e progresso: o controlo jurídico dos défices públicos como mecanismo de sustentabilidade econômica na União Europeia e no Brasil. Dissertação (Mestrado em Ciencias Juídico-Económicas) - Faculdade de Direito, Universidade do Porto, Portugal, 2018. Disponível em: https://repositorioaberto.up.pt/bitstream/10216/116960/2/299744.pdf

SEGUNDO, H. DE B. M. Emenda Constitucional 95/2016 e o teto dos gastos públicos. Revista Controle - Doutrina e Artigos, v. 15, n. 2, 22-40, 18 mai. 2018.

\section{UK GOVERNMENT DEBT AND DEFICIT: MARCH 2019. Office of National} Statistics, 2019. Disponível em:

https://www.ons.gov.uk/economy/governmentpublicsectorandtaxes/publicspendi ng/bulletins/ukgovernmentdebtanddeficitforeurostatmaast/march2019. 
UK GOVERNMENT DEBT AND DEFICIT: SEPTEMBER 2019. Office of National Statistics, 2019. Disponível em:

https://www.ons.gov.uk/economy/governmentpublicsectorandtaxes/publicspendi ng/bulletins/ukgovernmentdebtanddeficitforeurostatmaast/september2019 https://www.sciencedirect.com/science/article/pii/S0041863313711463

VAROUFAKIS, Y. The global minotaur: America, Europe and the future of the global economy. London: Zed Books Ltd., 2015.

WRAY, L.R. Teoría monetaria moderna: manual de macroeconomía sobre los sistemas monetarios soberanos. España: Lola Books, 2015.

WRAY, L.R. Statement by L Randall Wray, Congressional Testimony:

Reexamining the Economic Costs of Debt. Hearing before the House Budget Committee, 20 nov. 2019, p. 21. Disponível em:

https://budget.house.gov/sites/democrats.budget.house.gov/files/documents/Wra y_Testimony.pdf.

ZIMMER, B. Crisis=danger+opportunity: The plot thickens. Language Log, 27 mar. 2007. Disponível em:

http://itre.cis.upenn.edu/ myl/languagelog/archives/004343.html 